\title{
Season of birth as predictor of atopic manifestations
}

\author{
L Nilsson, B Björkstén, G Hattevig, B Kjellman, N Sigurs, N-I M Kjellman
}

\begin{abstract}
The relation between month of birth, sensitisation, and manifestations of atopy was assessed in 209 children who were followed from birth to 12-15 years. Children born during the tree pollen season were less likely to develop allergic rhinoconjunctivitis, IgE antibodies to pollen, or a positive screening test for IgE antibodies (odds ratio $0.28,0.41,0.35$, respectively) than children born during the rest of the year. The prevalence of IgE antibodies to food and animal dander at 9 months and to atopic disease was higher in children born in the autumn and winter, that is, September to February, compared to the spring and summer (egg $20 \% v 6 \%$; milk $10 \% v 2 \%$ ). Thus sensitisation to pollen and allergic rhinoconjunctivitis is least common in children born in the spring, while birth in September to February is associated with an increased incidence of sensitisation to food and of atopic disease. (Arch Dis Child 1997;76:341-344)
\end{abstract}

Keywords: hypersensitivity; seasonal effect of birth

Early infancy seems to be a period of particular susceptibility to sensitisation, as indicated by epidemiological $^{12}$ and experimental studies. ${ }^{3}$ For example, the season of birth may affect the future development of allergy, ${ }^{12-12}$ particularly in children with a propensity to atopic manifestations. ${ }^{7}$

We have previously reported the temporal

Department of Paediatrics, University Hospital, Linköping, Sweden

L Nilsson

B Björkstén

N-I M Kjellman

Department of Paediatrics, Central Hospital, Skövde, Sweden

G Hattevig

B Kjellman

Department of Paediatrics, Central Hospital, Borås, Sweden

N Sigurs

Correspondence to: Dr Lennart Nilsson, Department of Paediatrics, University Hospital, 58185 Linköping, Sweden.

Accepted 8 November 1996 children had no immediate family history of atopy. Clinical examinations were conducted by one of us (MK) four times during the first 18 months of life and on six occasions between 18 months and 15 years of age. Selected results from the first years of life have been published previously. ${ }^{14-16}$

Group II consisted of 84 girls born between August 1977 and August 1978 at the Central Hospital in Skövde. They had a random heredity for allergy and they were followed prospectively for 12 years. This group was originally recruited to a study of $\mathrm{Rh}$ immunisation ${ }^{17}$ but was also subject to an extensive follow up with regard to the appearance of allergic disease and IgE antibodies. ${ }^{18-20}$

Among the 209 children in the two study groups, 58 had a double, 66 a single, and 85 no family history of atopic disease. Blood was drawn at 9 and 21 months, and at 4.5, 6.5, 9, and 12 or 15 years of age.

\section{DIAGNOSTIC CRITERIA}

Atopy was defined as the presence of circulating IgE antibodies against an allergen or the presence of atopic disease, or both.

The diagnosis of atopic dermatitis was based on the definition of Hanifin and Rajka, that is, a pruritic, chronic, or chronically relapsing dermatitis with typical morphology and distribution. ${ }^{21}$ Bronchial asthma was defined as three or more episodes of bronchial obstruction as verified by a physician at least once. Allergic rhinoconjunctivitis was defined as rhinitis and conjunctivitis appearing at least twice after exposure to a particular allergen and not related to infection. Urticaria was defined as allergic if appearing on at least two occasions within one hour after exposure to a particular allergen. Gastrointestinal allergy was defined as the appearance of diarrhoea, colicky pains, and/or vomiting after intake of a specific food on at least two occasions.

The clinical observations were made in two hospitals by two of us (MK, GH) over a long period. Therefore three of the investigators (MK, LN, NS) jointly scrutinised the diagnoses by studying case histories of patients selected at random from the two groups. This retrospective control of the diagnoses agreed well with the initial classification, as there were only minimal differences in opinion.

LABORATORY METHODS

All serum samples were kept at $-20^{\circ} \mathrm{C}$ until analysed. In all, $6274 \mathrm{IgE}$ antibody determinations were done on 1079 blood samples, employing Pharmacia CAP system (Pharmacia Diagnostics, Uppsala, Sweden $(n=4351)$ or two members of the immediate family (the parents or siblings) in 52 of them, while 38 children had one atopic family member and 35 
Table 1 Estimated probabilities of atopic disease at various ages in relation to season of birth and family history of atopic disease

\begin{tabular}{llllll}
\hline & & \multicolumn{3}{c}{ Family history of allergy } & \\
\cline { 3 - 5 } Age & Month born & None & Single & Double & Difference between seasons $(p)$ \\
\hline 9 months & Mar-Aug & 0.03 & 0.12 & 0.14 & \\
& Sept-Feb & 0.12 & 0.35 & 0.39 & $<0.001$ \\
4.5 years & Mar-Aug & 0.06 & 0.10 & 0.18 & \\
& Sept-Feb & 0.14 & 0.21 & 0.35 & 0.005 \\
& Mar-Aug & 0.14 & 0.24 & 0.37 & \multirow{2}{*}{ NS years $(0.08)$} \\
& Sept-Feb & 0.23 & 0.36 & 0.51 & \\
\hline
\end{tabular}

$\star^{\star}$ A double family history of allergy was associated with a significantly increased risk at all ages $(\mathrm{p}<0.01)$.
(72/209, 34\%), followed by allergic rhinoconjunctivitis $(54 / 209,26 \%)$, food allergy/urticaria $(33 / 209,16 \%)$, and bronchial asthma $(25 / 209$, $12 \%)$.

Atopic disease was more common among children who were born in the autumn and winter compared to the spring and summer (table 1), independent of the family history of allergy. This was particularly obvious early in life. Thus the risk was about threefold at 9 months $(\mathrm{p}<0.001)$.

The prevalence of allergic rhinoconjunctivitis was $11 \%$ at 12 to 15 years of age among children who were born between March and May, as compared to a rate of $29-34 \%$ among children born during any of the other seasons ( $p=0.008$, fig 1$)$. A positive multiallergen test was also less common at all ages among children born between March and May (fig 2) $(p=0.01$ to 0.05 , compared to the other seasons). The seasonal influence was even more obvious in children who were born between April and June, compared to the other seasons. Thus the prevalence rate of allergic rhinoconjunctivitis was $0 / 40$ and $18 / 159(11 \%)$ respectively at 4.5 years $(\mathrm{p}=0.03), 1 / 39(3 \%)$ and $24 / 163(15 \%)$ at 6.5 years $(\mathrm{p}=0.05)$, and $3 / 39(8 \%)$ and $49 / 157(31 \%)$ at $12-15$ years of age $(\mathrm{p}=0.003)$.

Immunoglobulin $\mathrm{E}$ antibodies to egg white, milk and wheat were more often encountered in children who were born between September and February, compared to those born between March and August, (for egg, p < 0.001 and for milk, $p=0.01$ ) and they more often had atopic dermatitis $(p=0.04)$. Sensitivity to egg white was particularly common in children who were born in October and November as compared to the rest of the year, $\mathrm{p}=0.005)$. Similarly, $17 / 152$ children (11\%) with $\operatorname{IgE}$ antibodies against animal dander at 4.5 years were born between September and February,

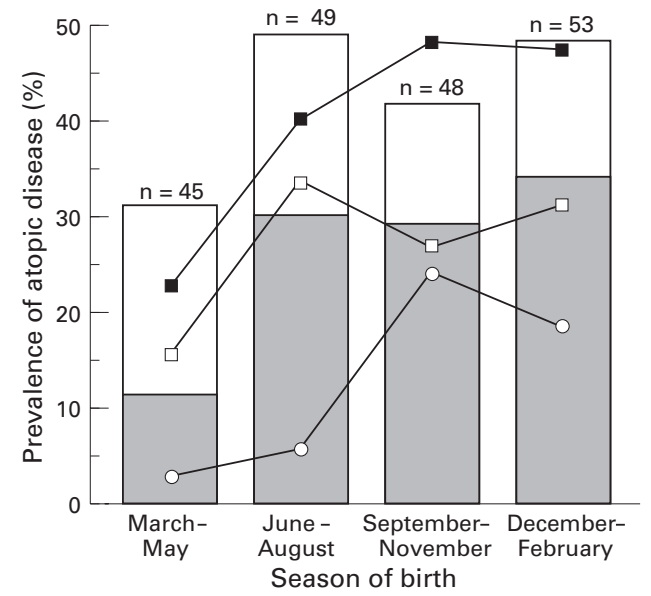

Figure 1 Prevalence (\%) of any atopic disease at 12-15 years of age (whole columns) and allergic rhinoconjunctivitis (shaded columns), and presence of circulating IgE antibodies against a mixture of allergens (filled squares), pollen (empty squares), and egg white (empty circles) in relation to season of birth in 209 children. Levels of statistical significance for differences in prevalence between children born between March and May as compared to the other months of the year: atopic disease NS $(p=0.06)$; allergic rhinoconjunctivitis $p=0.008$; multiallergen test, $p=0.006$; pollen, $p=0.04$; egg white, $p=0.05$. 


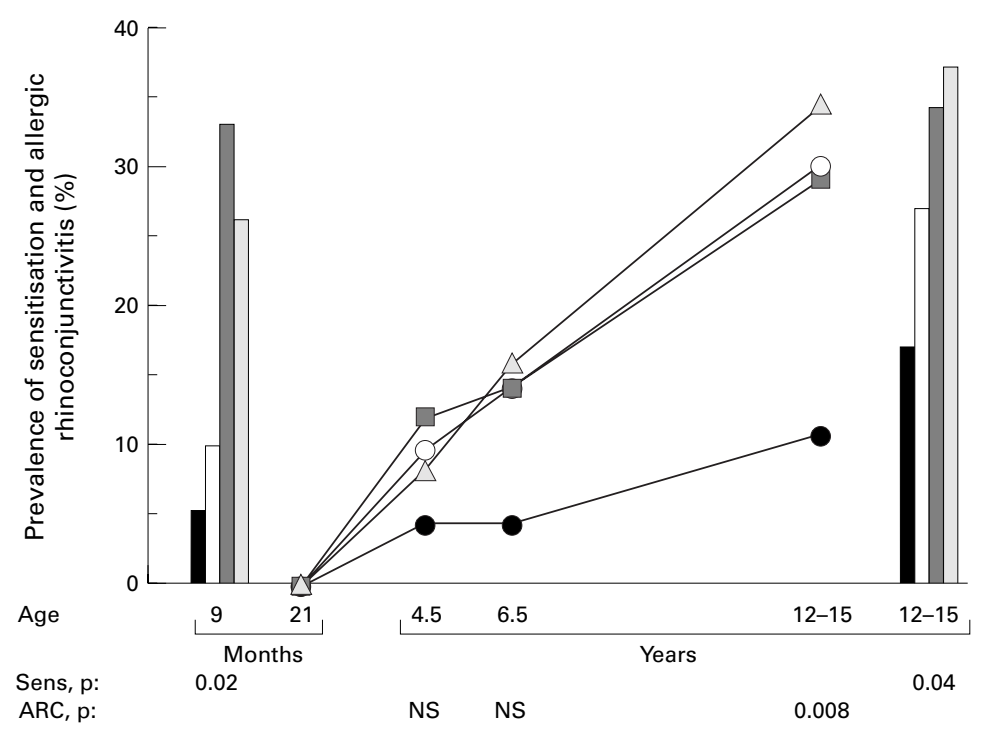

Figure 2 Period prevalence of sensitisation (Sens), as judged by a positive multiallergen test in relation to season of birth and period prevalence of allergic rhinoconjunctivitis (ARC) in 209 children who were followed up prospectively for 12 to 15 years. The p values refer to comparisons of the prevalence of sensitisation and atopic manifestations in children born during March to May compared to other times of the year. Black columns and circles denote infants born March to May, white symbols infants born Fune to August, dark grey columns and squares: infants born September to November, and light grey columns and triangles: infants born December to February.

as compared to $5 / 137$ children (4\%) born during the other six month period $(\mathrm{p}=0.02)$.

\section{Discussion}

The size of the study groups allowed us to detect an association between manifestations of atopy and season of birth. Thus we found an increased sensitisation rate to egg white and milk and a higher prevalence of atopic disease among children who were born between September and February. The study was not intended to be epidemiological, as children with a family history of allergy were greatly over-represented and the children were not randomised for the comparisons. The children included in the study were those whose parents had, at the time of the birth, an interest in having their child followed up in this prospective study. Hence children included in the study were born throughout all seasons.

Increased sensitisation to egg white among children born in the winter has previously been observed in a Dutch study ${ }^{4}$ and by us in another cohort of children. ${ }^{8}$ In the retrospective Dutch study including 78000 blood samples obtained from children for clinical reasons, the highest prevalence of IgE antibodies to egg white was recorded in patients who were born in September to February. In our recent prospective study, ${ }^{8}$ the increased risk was limited to children born between October and December. Reasons for this increased risk among children born in late autumn and winter remain unexplained.

Several previous studies have indicated that children born in the months before the pollen season more often develop sensitivity to pollen and allergic rhinoconjunctivitis than children born during the pollen season ${ }^{6-11}$ although this was not always the case. ${ }^{23}$ In the large Finnish study by Björkstén et al the highest risk for sensitivity to birch was seen among children born in the months preceding the pollen season. ${ }^{6}$ Similarly, the highest prevalence of sensitisation to mugwort was seen in children born in April and May, that is, some months before the mugwort pollen season, and the lowest prevalence was seen among children born in July and August. ${ }^{6}$ An explanation for this seasonality could be that mothers develop IgG antibodies to pollen during the pollen season which would suppress sensitisation, as indicated by experiments in rats. ${ }^{24}$ This possibility is supported by a very recent observation that the IgG antibody levels to the major birch antigen Bet $v 1$ in cord blood tended to be lower in babies who were born to atopic mothers outside the pollen season (MC Jenmalm et al, unpublished data). The seasonality of pollen sensitisation seems to be more evident in countries with a cold climate. ${ }^{25}$ Possibly, seasonal differences are not observed in countries where the major allergens are perennial.

The relation between season of birth and the development of allergy to seasonal allergens is further complicated by a Finnish study suggesting that weaning during the birch or grass pollen seasons was associated with a reduced risk for later development of allergic manifestations. ${ }^{26}$

In conclusion, infants born in the autumn and winter more often had $\operatorname{IgE}$ antibodies to egg white, milk, and wheat than children born in the spring and summer, and they more often developed atopic disease. In contrast, sensitisation to inhalant pollens and allergic rhinoconjunctivitis were less common in children born in the spring as compared to the other seasons. The phenotypic expression is influenced by genetic factors, maternal immunity (through the placenta and breast milk), time and dose of exposure, and adjuvant factors. The main reason for the seasonal effects found in this study remain to be clarified.

The study was supported by grants from the National Association for the Prevention of Asthma and Allergy (RmA), the Swedish Medical Research Council (No 7510) and Faculty of Health Sciences, University of Linköping. The IgE analyses were supported by grants from Pharmacia Diagnostics, Uppsala, Sweden.

1 Morrison-Smith J, Springett VH. Atopic disease and month of birth. Clin Allergy 1979;9:153-7.

2 Björkstén F, Suoniemi I, Koski V. Neonatal birch-pollen contact and subsequent allergy to birch pollen. Clin Allergy 1980;10:585-91.

3 Holt PG. Environmental factors and primary T-cell sensitisation to inhalant allergens in infancy: reappraisal of the role of infections and air pollution. Pediatr Allergy Immunol 1995;6:1-10.

4 Aalberse RC, Nieuwenhuys EJ, Hey M, Stapel SO. Aalberse RC, Nieuwenhuys EJ, Hey M, Stapel SO.
'Horoscope effect' not only for seasonal but also for 'Horoscope effect' not only for seasonal but also for

5 Åberg N. Birth season variation in asthma and allergic rhinitis. Clin Exp Allergy 1989;19:643-8.

6 Björkstén F, Suoniemi I. Time and intensity of first pollen contacts and risk of subsequent pollen allergies. Acta Med Scand 1981;209:299-303.

7 Croner S, Kjellman N-IM. Predictors of atopic disease: cord blood IgE and month of birth. Allergy 1986;41:68-70.

8 Nilsson L, Kjellman N-IM. Atopy and season of birth. Allergy 1996;51:138-9.

9 Pearson DJ, Freed DLJ, Taylor G. Respiratory allergy and month of birth. Clin Allergy 1977;7:29-33.

10 Pedersen PA, Rung Weeke ER. Month of birth in asthma and allergic rhinitis. Scand F Prim Health Care 1983;3/4:97-101.

11 Quoix E, Bessot JC, Kopferschmitt-Kubler MC, Fraisse P, Quoix E, Bessot JC, Kopferschmitt-Kubler MC, Fraisse P,
Pauli G. Positive skin tests to aero-allergens and month of
birth. Allergy 1988;43:127-31.

12 Wist M, Dold S, Reitmeir P, Stiepel E, von Mutius E. Month of birth and allergic disease at the age of 10 . Clin Exp Allergy 1992;22:1026-31. 
13 Sigurs N, Hattevig G, Kjellman B, Kjellman N-IM, Nilsson L, Björkstén B. Appearance of atopic disease in relation to 4 to 15 years. $\mathcal{F}$ Allergy Clin Immunol 1994;94:757-63.

14 Kjellman N-IM. Predictive value of high IgE levels in children. Acta Paediatr Scand 1976;65:465-71.

15 Kjellman N-IM, Johansson S. Soy versus cow's milk in infants with a biparental history of atopic disease: development of atopic disease and immunoglobulins from birth to 4 years of age. Clin Allergy 1979;9:347-58.

16 Kjellman N-IM. Development and prediction of atopic allergy in childhood. In: Boström $\mathrm{H}$, Ljungstedt $\mathrm{N}$, eds. Skandia International Symposia, 1982:52-73.

17 Hattevig G, Jonsson M, Kjellman B, Kjellman H, Messeter Le Tibblin $\mathrm{E}$. Screening of Rh-antibodies in Rh-negative emale infants with Rh-positive mothers. Acta Paediatr 1981;70:541-5.

18 Hattevig G, Kjellman B, Johansson SGO, Björkstén B Clinical symptoms and IgE responses to common food proteins in atopic and healthy children. Clin Allergy 1984;14:551-9.
19 Hattevig G, Kjellman B, Björkstén B. Clinical symptoms and IgE responses to common food proteins and inhalants
in the first 7 years of life. Clin Allergy 1987;17:571-8.

20 Hattevig G, Kjellman B, Björkstén B. Appearance of IgE antibodies to ingested and inhaled allergens during first 12 years of life in atopic and non-atopic children. Pediatr Allergy Immunol 1993;4:182-6.

21 Hanifin JM, Rajka G. Diagnostic features of atopic dermatitis. Acta Derm Venereol (Stockh) 1980;92(suppl):44-7.

22 Pastorello EA, Incorvaia C, Pravettoni V, Marelli A, Farioli $\mathrm{L}, \mathrm{Ghezzi} M$. Clinical evaluation of CAP system and RAST in the measurement of specific IgE. Allergy 1992;47:463-6.

23 Sibbald B, Rink E. Birth month variation in atopic and non atopic rhinitis. Clin Exp Allergy 1990;20:285-8.

24 Jarrett $\mathrm{E}$, Hall $\mathrm{E}$. IgE suppression by maternal IgG. Immunology 1983;48:49-58.

25 Björkstén F, Suoniemi I. Dependence of immediate hypersensitivity on the month of birth. Clinical Allergy 1976;6:165-71.

26 Saarinen UM, Kajosaari M, Backman A. Birch pollen allergy in children. Allergy 1982;37:345-50. 